\title{
Desenvolvimento de um modelo de banco de dados PARA SISTEMATIZAÇÃO DE PROGRAMAS DE GERENCIAMENTO INTEGRADO DE RESÍDUOS SÓLIDOS EM SERVIÇOS DE LIMPEZA PÚBLICA
}

\author{
DEVELOPMENT OF A DATA BASE MODEL FOR THE SYSTEMATIZATION OF \\ INTEGRATED MUNICIPAL SOLID WASTE MANAGEMENT
}

\begin{abstract}
MARIA CRISTINA Borba BRAGA
Engenheira Química (UFPR). PhD em Tecnologia Ambiental pelo Imperial College London - Universidade de Londres. Professora Adjunta do Departamento de Engenharia Química. Coordenadora do Laboratório de Engenharia Ambiental Prof. Francisco Borsari Netto. Vice Coordenadora do Programa de Pós-Graduação em Engenharia de Recursos Hídricos e Ambiental da Universidade Federal do Paraná
\end{abstract}

\section{Sonia Iara Portalupi Ramos}

Engenheira Civil (UFPR). Mestre em Engenharia de Recursos Hídricos e Ambiental (UFPR)

Recebido: 21/03/05 Aceito: 24/04/06

\section{RESUMO}

Este estudo foi levado a efeito em 17 municípios do Estado do Paraná, com população de até 250 mil habitantes, escolhidos em função de características peculiares das regióes do Estado em que se localizam. A pesquisa abordou o levantamento de dados em cada um dos municípios em relação aos aspectos físico-ambientais, sócio-econômicos e estruturais, e estendeu-se também aos aspectos administrativos, operacionais e sociais com o objetivo de desenvolver um modelo de banco de dados para sistematizar as operaçôes e serviços de limpeza pública. O desenvolvimento e a organização do banco de dados facilitaram a visualização das informações e a elaboração de um diagnóstico que poderá servir como ferramenta para a tomada de decisões e, também, de apoio à elaboração de projetos de gerenciamento integrado de resíduos sólidos nos âmbitos municipal e estadual.

PALAVRAS-CHAVE: Resíduos sólidos urbanos, gerenciamento integrado de resíduos sólidos, modelo de banco de dados para resíduos sólidos urbanos, sistematização do gerenciamento de resíduos sólidos urbanos.

\begin{abstract}
This research was carried out in 17 municipalities of the State of Parana, Brazil, with population up to 250 thousand inhabitants. The municipalities were chosen based on peculiar characteristics of six different regions of the State. The development of the field research was carried out through data collection of physiographic and environmental, socio-economical and structural aspects of each community. This research also considered administrative, operational and social aspects with the aim to develop a data base model for the systematization of municipal solid waste programmes and services. The resulting data base facilitated both the diagnosis and the visualization of all system input information. It is worth mentioning that the results produced by this research can be used as a managerial tool for decision makers at municipal and state levels with regard to integrated solid waste programmes.
\end{abstract}

KEYWORDS: Municipal solid waste, integrated solid waste management, data base model for solid waste management, systematization of solid waste management.

\section{INTRODUÇÃO}

O problema dos resíduos sólidos urbanos é tema de interesse mundial, e tem sido tratado como prioritário, juntamente com os problemas relativos à água e ao meio ambiente.

O planejamento estratégico regional de um sistema integrado de gerenciamento de resíduos sólidos é uma etapa crítica que, se não for ela- borado de maneira apropriada, poderá levar à concepção de um sistema de gerenciamento ineficiente. Portanto, o planejamento regional afeta o projeto, a implantação e a implementação, além da eficiência da totalidade dos sistemas gerencial e operacional (El-Fadel e Najm, 2002). Assim, a otimização da estratégia do gerenciamento integrado para uma região requer o conhecimento das alternativas e tecnologias disponíveis de gerenciamento dos resíduos, custos econômicos e ambientais associados a essas alternativas e sua aplicabilidade para uma região específica, sendo importante que o administrador tenha como base um planejamento regional otimizado de gerenciamento para atingir metas pré-estabelecidas.

Freqüentemente, os administradores têm de contar com um modelo de otimização para avaliar o impacto 
do balanço de massa, a limitação da capacidade operacional e a disponibilidade de local, bem como para analisar diferentes opçōes de alternativas para a seleção de custos e de gerenciamento ambientalmente seguro (El-Fadel e Najm, 2002). Neste sentido, cada estado brasileiro, a sua maneira, tem encontrado alternativas para aprimorar o sistema de limpeza pública, ficando limitado, entretanto, pela falta de dados técnicos relativos à geração, composição e conseqüente operacionalização dos resíduos sólidos urbanos (Braga e Bonetto, 1993; CETESB, 2000 a e b; Lima, 2001; ABLP, 2002; Jucá, 2002; Gomes e Martins, 2003; IAP, 2003; Langue et al, 2003).

Entretanto, a falta de atualização e a não sistematização das informaçōes sobre os resíduos sólidos no Brasil têm representado um grave empecilho para o conhecimento mais amplo da situação destes serviços, o que dificulta o estabelecimento de políticas públicas para o desenvolvimento desta área e, também, para direcionar a atuação das entidades governamentais ou privadas que tratam a questão (Ruberg e Philippi, 1999; Brollo e Silva, 2000; Ribeiro e Comin, 2001). Outro fator importante e que deve ser considerado é a falta de dados consistentes e confráveis sobre a geração dos resíduos e os serviços prestados em municípios do interior dos estados, além do controle operacional e funcional das atividades de limpeza pública, pois isso dificulta a administração e o gerenciamento adequado do sistema (IBGE, 2000; Gomes e Martins, 2003; IAP, 2003; CETESB, 2000 a).

Portanto, para que seja definido um programa de gerenciamento integrado, que apresente possibilidade de operacionalização dos serviços e programas, existe a necessidade de um planejamento estratégico, o qual depende da obtenção de dados consistentes e reais da situação dos resíduos sólidos urbanos gerados pela população local. Portanto, um programa para ser considerado efetivamente funcional deve ser baseado em um banco de dados preciso, organizado e atualizado (MacDonald, 1996).

Com estas condições definidas e com os resultados das visitas aos municípios adotados como estudo de caso para o desenvolvimento deste trabalho, foi possível observar a necessidade da estruturação e da sistematização do gerenciamento dos resíduos sólidos urbanos por parte das administraçōes municipais no Estado do Paraná. Desta forma, o objetivo principal deste estudo, foi estabelecido para que os resultados do trabalho pudessem ser utilizados para propor um sistema técnicoorganizacional para o gerenciamento de resíduos sólidos urbanos que visasse a identificação de ações estratégicas de gestão e, também, que servisse para diagnosticar as formas de disposição final adotadas em municípios do interior do Estado do Paraná.

\section{METODOLOGIA}

Para ao desenvolvimento deste trabalho, a metodologia adotada foi divida em duas fases:

- Fase 1 - Levantamento das Informaçōes Disponíveis - esta fase envolveu uma ampla análise dos dados referentes à forma de disposição final dos resíduos sólidos urbanos no Estado do Paraná; disponibilizados por órgãos do governo e, também, das informaçōes obtidas a partir da aplicação de questionários e do levantamento fotográfico para cada município estudado;

- Fase 2 - Concepção do Banco de Dados - esta fase constituiu-se na estruturação de um modelo de banco de dados para os municípios do Estado do Paraná, com o propósito de ser utilizado como uma ferramenta de auxílio à gestão e ao gerenciamento de resíduos sólidos urbanos.

\section{Levantamento das informações disponíveis}

Objetivando agregar experiência e recursos técnicos para a elaboração do banco de dados, denominado Gerenciamento Integrado de Residuos Urbanos, a partir daqui, identificado como GIRU, primeiramente foi efetuado um diagnóstico da situação atual em relação à limpeza pública nos municípios do interior do Estado do Paraná. Esta etapa, relacionada à primeira fase do trabalho, envolveu uma análise detalhada dos dados disponibilizados referentes à forma de disposição final dos resíduos sólidos urbanos. Este levantamento foi efetuado para os 399 municípios do Estado, a partir de informaçóes fornecidas pelo órgão estadual responsável, o Instituto Ambiental do Paraná - IAP que, através do Departamento de Licenciamento de Atividades Poluidoras - DLP, forneceu o Diagnóstico da Situação da Dispo- sição de Resíduos Sólidos Urbanos e Hospitalares do Estado do Paraná (IAP, 2003). Este relatório forneceu informaçôes sobre a forma de destinação final em cada um dos 399 municípios, além de uma planilha de açôes tomadas pelo IAP em relação à disposição dos resíduos.

$\mathrm{Na}$ segunda etapa desta fase foi efetuado um levantamento de campo, para o qual o espaço amostral foi bastante reduzido, tendo sido considerados apenas 17 municípios do interior do Estado, com população até $250 \mathrm{mil}$ habitantes. Estes municípios foram escolhidos em função de características peculiares das regiōes em que se localizam. Esta delimitação foi função de uma avaliação prévia dos municípios, realizada com dados disponibilizados por órgãos ambientais diretamente ligados ao gerenciamento dos resíduos sólidos. Alguns dos quesitos analisados foram as formas de gerenciamento e destinação final dos resíduos, os programas de destaque estadual, as iniciativas inéditas de reciclagem ou de educação ambiental, entre outros.

A abrangência espacial deste trabalho recaiu sobre as seis macrorregiōes do Estado do Paraná, com denominação pelo Instituto Paranaense de Desenvolvimento Econômico e Social - IPARDES de Regionalização de Gestão e Planejamento - RGP, conforme Figura 1(IPARDES, 2004), e foi definida como amostragem intencional, com a preocupação inicial de que todas as regiōes estivessem representadas por, no mínimo, um município e atendendo a critérios de ordem técnica como densidade populacional, atividades e características sócio-econômicas, entre outras. Os municípios estudados foram: Guaratuba e Paranaguá (RGP I - Curitiba); União da Vitória (RGP II - Ponta Grossa); Jacarezinho, Barra do Jacaré e Andirá (RGP III - Londrina); Ivaiporã (RGP IV - Guarapuava); Cianorte (RGP V - Maringá); Toledo, Cascavel, Boa Vista da Aparecida, Capitão Leônidas Marques, Boa Esperança do Iguaçu, Cruzeiro do Iguaçu, Nova Prata do Iguaçu, Salto do Lontra, São Jorge do Oeste (RGP VI - Cascavel).

A pesquisa abordou o levantamento de dados em cada um dos municípios em relação aos aspectos físico-ambientais, sócio-econômicos, estruturais e, também, estendeu-se aos aspectos administrativos, operacionais e sociais. Com a finalidade de possibilitar 
a obtenção de dados suficientemente representativos, as informaçóes foram levantadas através de visitas técnicas, levantamento fotográfico e aplicação de questionários. A Tabela 1 apresenta a estrutura geral do questionário aplicado.

\section{Concepção do banco de dados}

Esta fase constituiu-se da estruturação de um modelo de banco de dados sobre os resíduos sólidos urbanos nos municípios do Estado do Paraná, e teve a finalidade de desenvolver uma ferramenta de auxílio à gestão e gerenciamento dos serviços de limpeza pública. Para estruturar o banco de dados foram utilizados os aplicativos Microsoft Access e Visual Studio 6.0 Interprise, que propicia a criação da interface de interação com o usuário.

O primeiro passo para a elaboração do banco de dados foi definir cada tabela, individualmente. Cada tabela foi baseada no questionário aplicado em cada município estudado, como apresentado na Figura 2 e, posteriormente, para individualizar cada registro e torná-lo único, foi definida uma chave primária em cada tabela gerada. Um exemplo de chave primária é o código do município, pois cada município só pode ser identificado por um único código.

Em cada uma das tabelas também foi criada uma chave estrangeira, através da qual é feita a interligação entre duas tabelas distintas e a correlação entre os dados. As interfaces, que são as janelas visualizadas a partir das informaçôes registradas no banco de dados, e que possibilitam a interatividade do usuário com o banco de dados, foram desenvolvidas em Visual Studio 6.0 Interprise.

O modelo de banco de dados GIRU, e sua representação através de janelas de diálogo, foi concebido visando a elaboração e apresentação do diagnóstico ambiental atualizado da situação dos resíduos sólidos no Estado do Paraná.

\section{RESULTADOS}

Como resultado desta pesquisa, cujo objetivo foi desenvolver um modelo de banco de dados que pudesse ser operado de maneira amigável, na tela de abertura do programa é mostrado o mapa temático com o resultado da avaliação das condições de operação

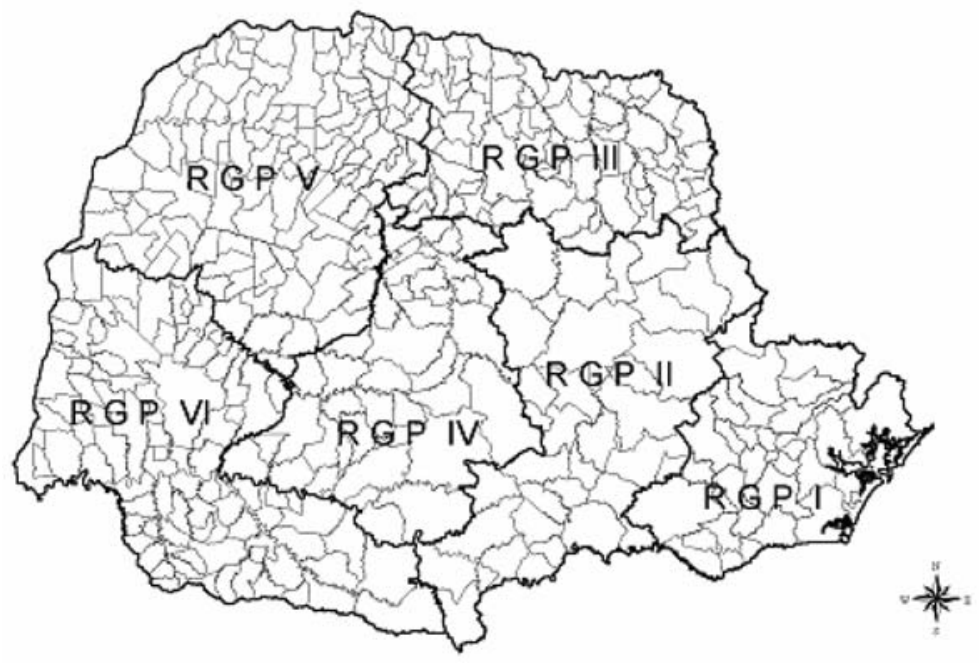

Fonte: IPARDES (2003)

Figura I - Mapa da Regionalização de Gestão e Planejamento do Estado do Paraná

Tabela I - Estrutura geral do questionário aplicado aos municípios

\begin{tabular}{|c|c|c|}
\hline Questões & Referentes a: & Dados \\
\hline 1 & Dados do Município & Cadastral \\
\hline 2 a 5 & $\begin{array}{c}\text { Informaçôes gerais sobre os resíduos } \\
\text { sólidos urbanos }\end{array}$ & $\begin{array}{c}\text { Geração } \\
\text { Caracterização } \\
\text { Composição }\end{array}$ \\
\hline 6 & Serviços oferecidos pela Prefeitura & Coleta \\
\hline 7 a 9 & Custos envolvidos & Forma de cobrança \\
\hline $10-11$ & Funcionários & $\begin{array}{l}\text { Administrativo } \\
\text { Garis }\end{array}$ \\
\hline 12 & Processos de seleção e tratamento & $\begin{array}{c}\text { Triagem } \\
\text { Reciclagem } \\
\text { Compostagem }\end{array}$ \\
\hline $13-14$ & Coleta e transporte & $\begin{array}{l}\text { Pessoal } \\
\text { Freqüência } \\
\text { Controle }\end{array}$ \\
\hline 15 a 18 & Destinação final & Forma de destinação \\
\hline 19 & Resíduos dos serviços de saúde & Destinação \\
\hline 20 & Varrição & $\begin{array}{l}\text { Pessoal } \\
\text { Freqüência }\end{array}$ \\
\hline 21 & Capina e poda & Freqüência \\
\hline 22 & Entulho da construção civil & Destinação \\
\hline 23 & Avaliação do sistema & Desempenho \\
\hline
\end{tabular}




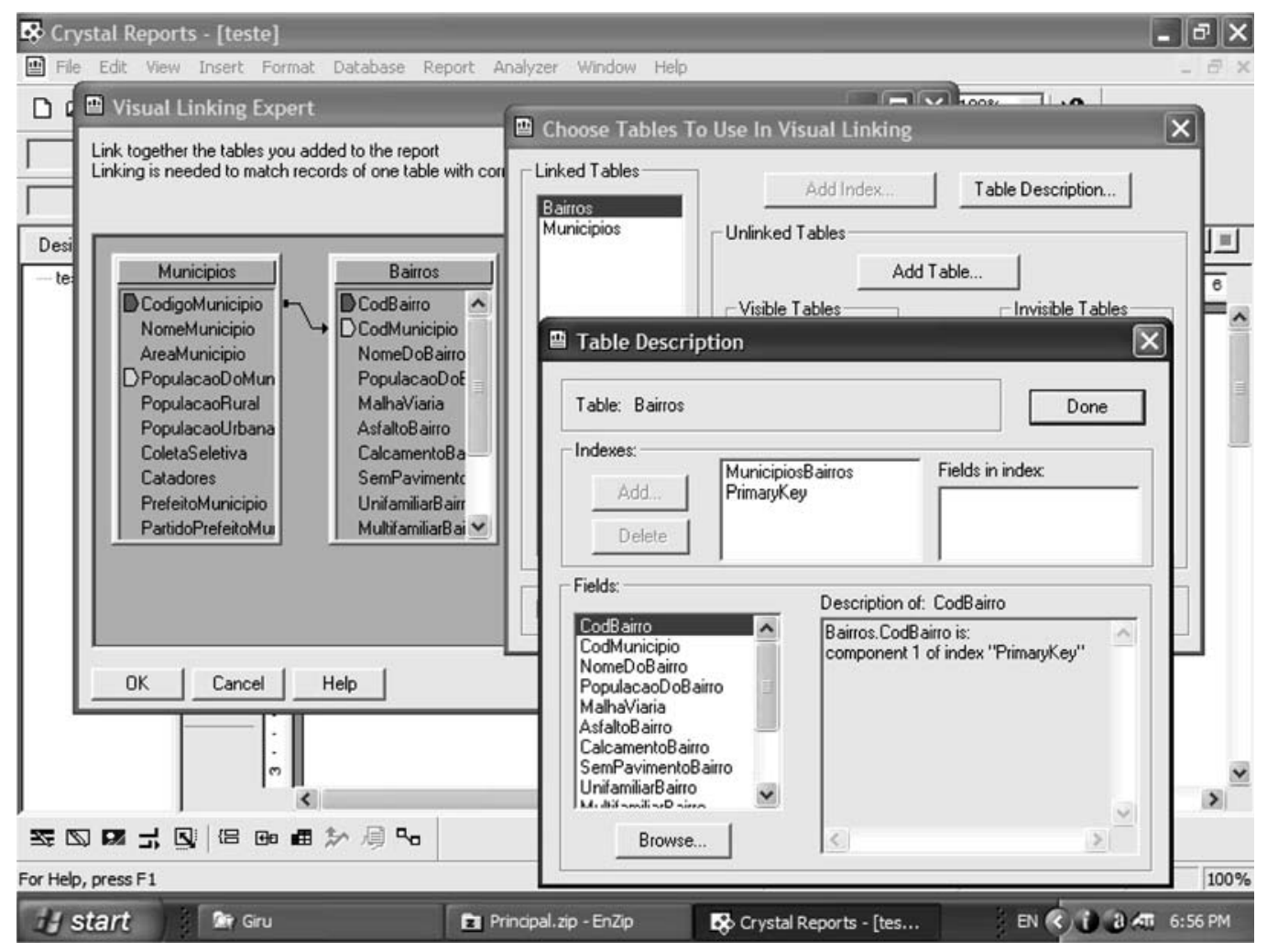

Figura 2 - Banco de Dados GIRU - Tabelas de relacionamentos

das áreas de disposição final dos resíduos sólidos urbanos no Estado do Paraná. Este mapa resultou do cruzamento entre as informaçōes fornecidas pelo Diagnóstico da Atual Situação da Disposição de Resíduos Sólidos Urbanos e Hospitalares do Estado do Paraná (IAP, 2003) e os cálculos realizados para definir o Índice de Qualidade de Resíduos para aterros ou valas - IQR Aterro ou Vala, a partir das informações obtidas em campo.

$\mathrm{Na}$ tela inicial do programa, na barra de ferramentas, constam os menus arquivo, cadastro e ferramentas, através dos quais são feitas as inserções e consultas sobre a situação de cada município como mostra a Figura 3.

No menu cadastros, o sub-menu $m u$ nicípios abre as telas de informações sobre o município específico que, por sua vez, tem sua barra de menu e de ferramentas para executar as funções inerentes ao controle de cada um dos 399 municípios.

Após a escolha de um município, com um clique do "mouse" sobre a respectiva área no mapa, também podem ser mostradas as imagens fotográficas que podem ser inseridas através do menu ferramentas,

Sobre o mapa diagnóstico, para identificar um município, deve-se arrastar o cursor do "mouse" e posicioná-lo sobre a área do município de interesse. Esta operação evidenciará tanto o nome quanto o valor do IQR, que aparecerão na extremidade superior direita, abaixo da palavra PARANÁ (Figura 4).

A partir deste mapa diagnóstico e das ferramentas de inserção e manipulação de dados é possível apenas avaliar a situação de cada município ou, em caso de necessidade operacional, adicionar ou remover informaçôes sobre os programas, serviços e/ou recalcular o IQR.

A tela cadastros básicos tem por função permitir o cadastramento dos dados referentes a cada município. Esta tela está dividida em 18 comandos como bairros, categorias de coleta, distritos populacionais, entulhos, etimativas populacionais, feiras, frotas, frota hospitalar, funcionários, geografia e relevo, máquinas e equipamentos, codificação dos municípios, outros serviços, resíduos gerados, resíduos de saúde e setores, sendo que cada uma dessas funções abre uma tela que, por sua vez, possui uma barra de ferramentas que pode acionar outras telas.

O comando bairros, por exemplo, abre a janela de entrada de dados sobre bairros que, por sua vez, pode acionar a janela limpeza dos bairros, como mostra a Figura 5.
Para esta função, são previstas entradas de dados referentes a todas as atividades de limpeza urbana de um dado município, como as de varrição, poda de árvores, limpeza de locais destinados a feiras, limpeza de córregos, entre outros. O comando outros serviços, na barra de ferramentas, apresenta a opção de abertura de outros cadastros como o de varrição, conforme mostra a Figura 6. Para o caso de municípios maiores, esta entrada de dados pode ser por bairro ou por setor.

A Figura 7 apresenta o agrupamento de outras janelas de inserção de dados como cadastros básicos.

O banco de dados GIRU prevê a inserção de dados para todos os municípios do Estado do Paraná, possibilita o armazenamento de imagens para cada município individualmente e, também, a emissão de relatórios via Internet.

O acompanhamento das atividades de limpeza urbana, dos valores de geração de resíduos bem como os indicadores de qualidade de aterros sanitários, de cada município, pode ser efetuado sem dificuldades por administradores públicos e pesquisadores, bastando que o banco de dados seja disponibilizado em rede. 


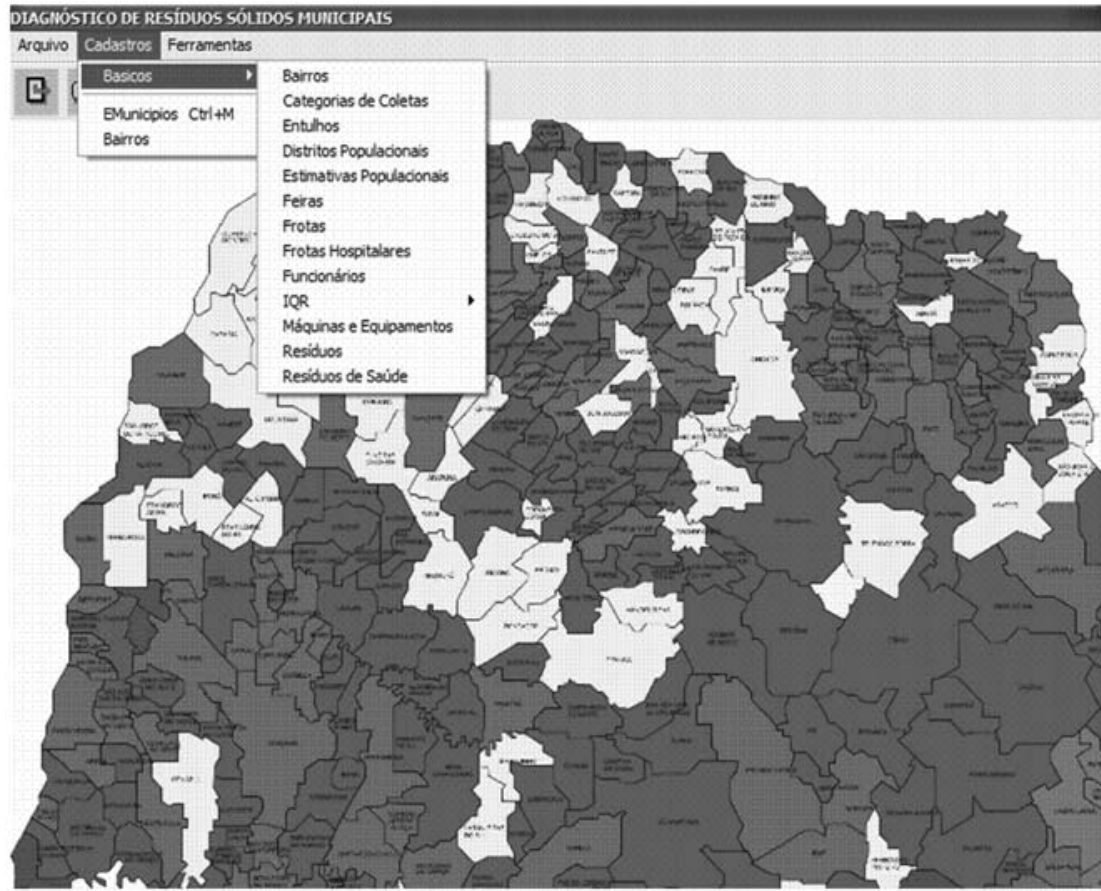

Figura 3 - Tela inicial do modelo de banco de dados - GIRU

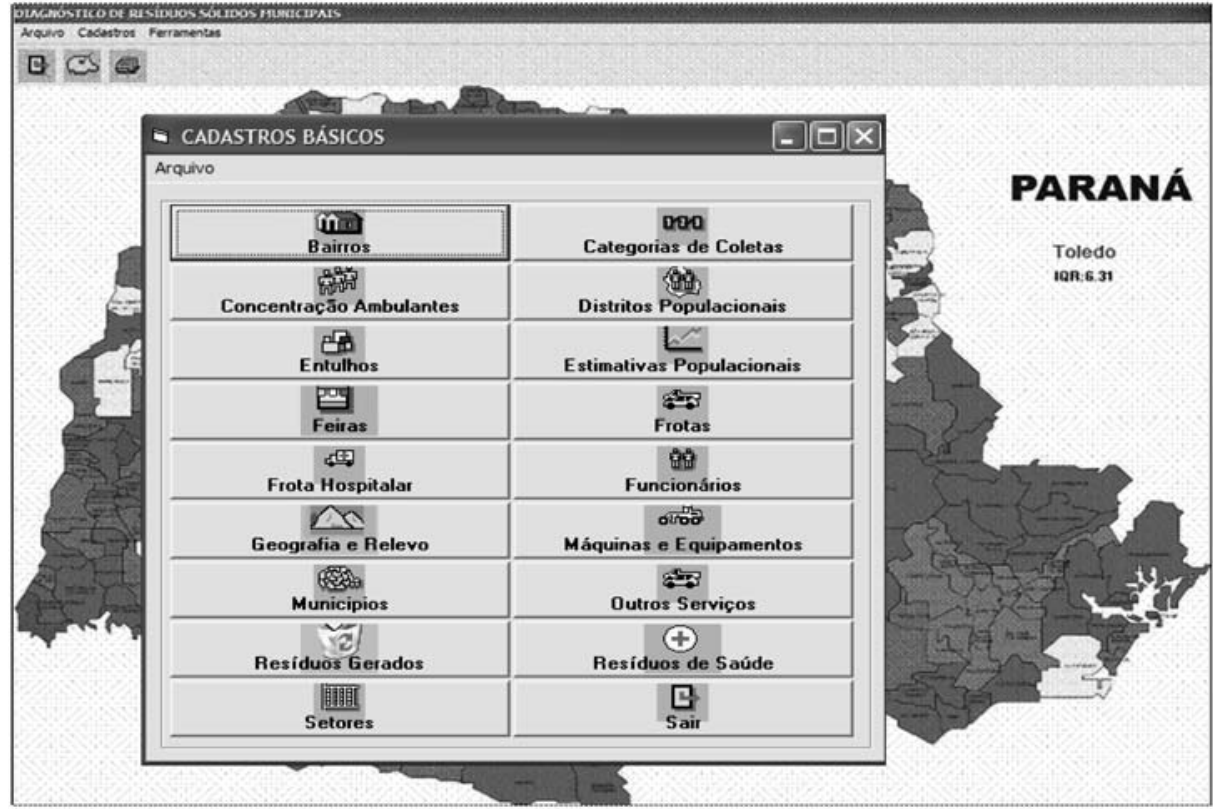

Fonte: IPARDES (2003)

Figura 4 - Tela inicial do banco de dados: Mapa Diagnóstico, apresentando a janela de inserção de dados Cadastros Básicos 


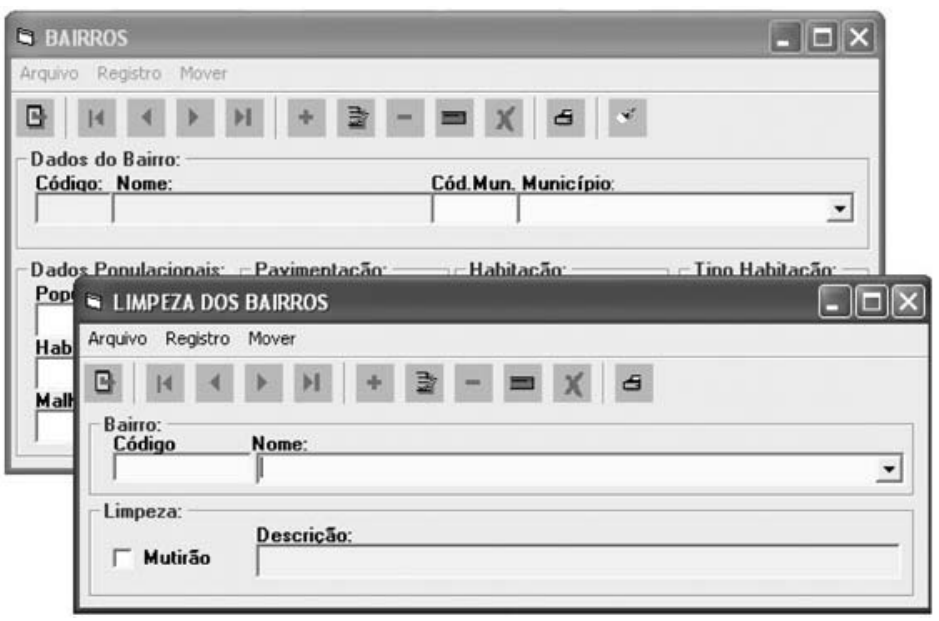

Figura 5 - Janela de inserção de dados: cadastros básicos - bairros

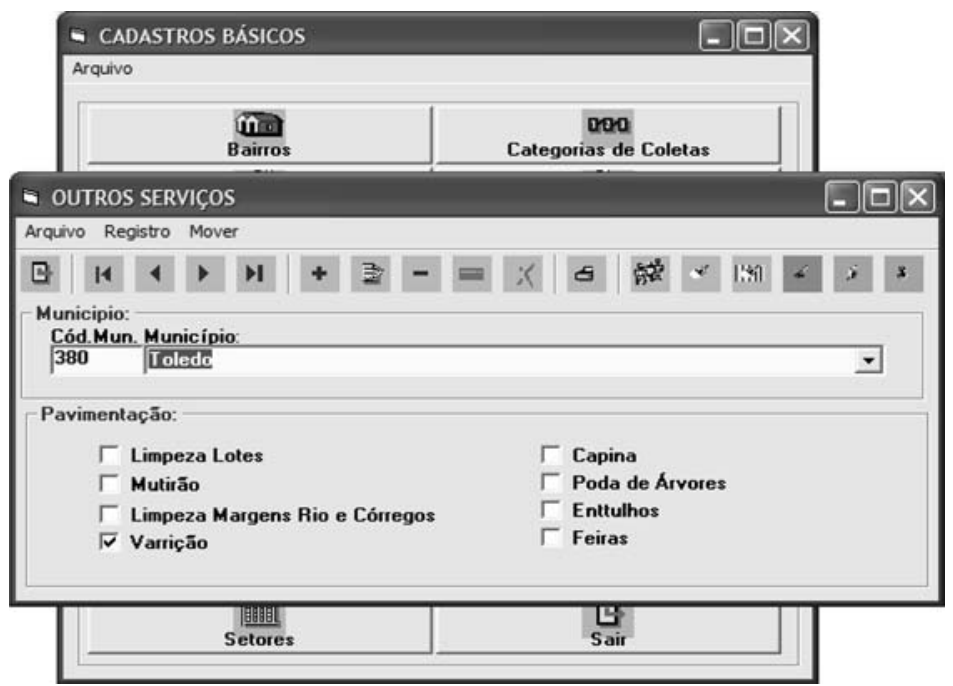

Figura 6 - Janela de inserção de dados: cadastro básicos - outros serviços

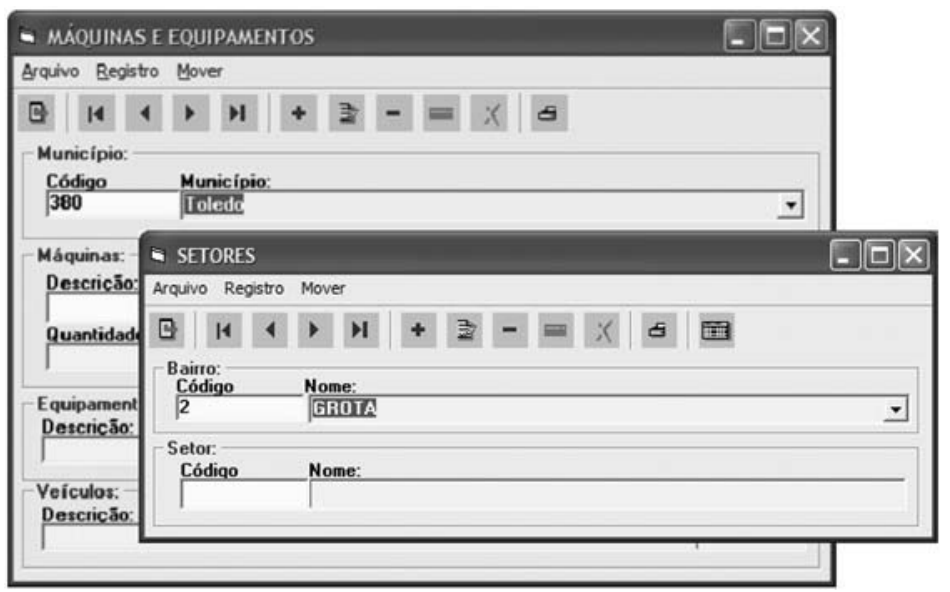

Figura 7 - Agrupamento de janelas de inserção de dados de cadastros básicos 


\section{CONCLUSÕES E RECOMENDAÇỐES}

Durante o levantamento bibliográfico e após a aplicação dos questionários nos 17 municípios adotados como estudo de caso, na fase de coleta de dados, foi possível constatar a dificuldade que as administraçôes municipais encontram para gerenciar os programas e serviços relacionados à limpeza pública, principalmente devido à falta de dados ou ao desconhecimento de melhores práticas para otimizar os serviços, incluindo a coleta e a destinação final dos resíduos sólidos urbanos. Também foi observado que existia uma grande dificuldade para elaborar um plano estratégico que pudesse garantir, de forma satisfatória, o gerenciamento e a coordenação dos serviços relacionados aos resíduos sólidos urbanos, fator preponderante para justificar a importância do desenvolvimento deste trabalho.

Com a pesquisa de campo, que serviu de experiência e alimentou a base de dados, foi possível observar as dificuldades que os corpos técnicoexecutivo e de fiscalização têm para administrar os serviços de limpeza publica, dificuldade esta resultante do desencontro de informaçôes e, muitas vezes, da total falta de organização na observação e repasse das informações.

Desta forma, o modelo de banco de dados GIRU foi elaborado com base na constatação da falta de organização para a administração das informaçōes existentes ou necessárias para o gerenciamento dos programas e serviços de limpeza pública. Portanto, a aplicação deste modelo, como ferramenta de gerenciamento, pode facilitar a coleta e o repasse dos dados, pois prevê a inserção de dados para todos os municípios do Estado do Paraná, possibilita armazenar imagens para cada município individualmente e também emitir relatórios via Internet. $\mathrm{O}$ acompanhamento das atividades de limpeza pública, dos valores de geração de resíduos bem como os indicadores de qualidade dos aterros sanitários, de cada município, podem ser facilmente efetuados por administradores, pesquisadores e pessoas interessadas nesse setor, bastando que esse banco de dados seja disponibilizado em rede.

A previsão de continuidade deste trabalho está no tratamento estatístico dos índices de qualidade e na definição de um modelo matemático que represente o sistema com o propósito de padronizar as respostas e fornecer subsídios para a tomada de decisão na implantação de um modelo de sistema de gerenciamento de resíduos sólidos urbanos.

\section{AGRADECIMENTOS}

As autoras agradecem a cooperação das Prefeituras dos 17 municípios onde foi desenvolvida a pesquisa, ao IAP - Instituto Ambiental do Paraná e ao IPARDES - Instituto Paranaense de Pesquisa e Desenvolvimento Econômico e Social pelas informaçóes fornecidas, e à Capes - Coordenação de Aperfeiçamento de Pessoal de Nível Superior pelo suporte financeiro.

\section{REFERÊNCIAS}

ABLP - ASSOCIAÇÃO BRASILEIRA DE RESÍDUOS SÓLIDOS E LIMPEZA PÚBLICA. Elaboração de planilhas de custos dos serviços de limpeza pública. São Paulo: ABLP, 2002.

BRAGA, M.C.B.; BONETTO, E.R. Solid waste management in Curitiba, Brazil - alternative solutions. The Journal of Resource Management and Technology, Philadelphia, v. 21, n.1, p. 11-14, Mar. 1993.

BROLlo, M. J. \& SILVA, M. M. Politica e gestão ambiental em resíduos sólidos. Divisão e análise sobre a atual situação do Brasil. In: 210 CONGRESSO BRASILEIRO DE ENGENHARIA SANITÁRIA E AMBIENTAL, Anais. 1 CD-ROM. 2000

CETESB - COMPANHIA DE TECNOLOGIA DE SANEAMENTO AMBIENTAL. Inventário estadual de resíduos sólidos domiciliares. São Paulo: CETESB-DOESP, 731 p. Relatório Síntese. 2000.

EL-FADEL, M. \& NAJM, M. A. Economic and environmental optimization of integrated solid waste systems. The Journal of Solid Waste Technology and Management, Chester, v. 28, n. 4, 222-232, nov. 2002.

GOMES, L. P. \& MARTINS, F. B. Projeto, implantação e operação de aterros sustentáveis de resíduos sólidos urbanos para municípios de pequeno porte. In: CASTILHOS JUNIOR, A. B. Projeto, implantação e operação de aterros sustentáveis de resíduos sólidos urbanos para municípios de pequeno porte. Rio de Janeiro, ABES, Projeto PROSAB, p. 51-105 2003.

IAP - INSTITUTO AMBIENTAL DO PARANÁ. Departamento de Licenciamento de Atividades Poluidoras. Diagnóstico da atual situação da disposição de resíduos sólidos urbanos e hospitalares do Estado do Paraná. Curitiba: SEMA-IAP, agosto, 350 p. Relatório Técnico. 2003.

IBGE - INSTITUTO BRASILEIRO DE GEOGRAFIA E ESTATÍSTICA. Censo demográfico 2000. Disponível em <http://www.ibge.gov.org. htm>, Acessado em: 12 mar. 2003.

IPARDES - INSTITUTO PARANAENSE DE DESENVOLVIMENTO ECONÔMICO
E SOCIAL. Base Cartográfica, 1 CD-ROM. 2003.

JUCÁ, J. F. T. Destinação final dos residuos sólidos no Brasil: situação atual e perspectivas. In: X SIMPÓSIO LUSO-BRASILEIRO DE ENGENHARIA SANITÁRIA E AMBIENTAL, Braga. Anais. Portugal, 1 CD-ROM. 2002.

LANGUE, L.C.; SIMÔES. G.F.; \& FERREIRA, C.F.A. Aterro sustentável: um estudo para a cidade de Catas Altas, MG. In: CASTILHOS JUNIOR, A. B. Alternativas de disposição de resíduos sólidos urbanos para pequenas comunidades. Rio de Janeiro, ABES, Projeto PROSAB, p. 143-197. 2003.

LIMA, J. D. Gestão de resíduos sólidos urbanos no Brasil. Campina Grande: ABES, 231 p. 2001.

MACDONALD, M. Solid waste management models: a state of the art review. The Journal of Solid Waste Technology and Management, Chester, v. 23, n. 2,. 73-83, may 1996.

RIBEIRO, H. \& COMIN, H. Novos instrumentos de gestão ambiental urbana. São Paulo: Ed. USP, 153 p. 2001.

RUBERG, C.\& PHILIPPI JR, A. O gerenciamento de residuos sólidos domiciliares: problemas $e$ soluçôes - um estudo de caso. Rio de Janeiro. In: $20^{\circ}$ CONGRESSO BRASILEIRO DE ENGENHARIA SANITÁRIA E AMBIENTAL, Anais. ABES, 1 CD-ROM. 1999.

Endereço para correspondência:

Maria Cristina Borba Braga Departamento de Hidráulica e Saneamento

Universidade Federal do Paraná Centro Politécnico - Jardim das Américas Caixa Postal I 901 I 8I53 I-990 Curitiba - PR - Brasil Tel.: (4I) 336I-3045

Fax: (4I) 336I-3I 43

E-mail: crisbraga@avalon.sul.com.br 